\title{
Cinema, realismo e revelação: um diálogo com Paul Tillich e André Bazin
}

\author{
Joe Marçal G. Santos*
}

\section{RESUMO}

Este artigo tem como objetivo identificar os principais conceitos da teologia da arte de Paul Tillich, a fim de reconhecer possibilidades e/ou limites para uma abordagem teológica da arte cinematográfica baseada neste arcabouçou teórico. Destacaremos uma correlação entre a compreensão de Tillich do realismo na arte contemporânea e a teoria do cinema de André Bazin. Para esses autores, a autenticidade crítica e criativa da arte depende de sua relação temporal e espacial com o real, ainda que o faça de forma simbólica. A fim de desenvolver este estudo, em um primeiro momento, apresentaremos argumentos de Bazin a favor do realismo cinematográfico e, então, estabeleceremos conexões conceituais com Paul Tillich.

Palavras-chave: Cinema. Teologia da cultura. André Bazin. Paul Tillich.

\section{FILM, REALISM AND REVELATION: A DIALOGUE WITH PAUL TILLICH AND ANDRE BAZIN}

\begin{abstract}
This article aims to identify main concepts of Paul Tillich's Theology of art in order to recognize possibilities and/or limits to a theological approach of the cinematographic art based on this Theology. We will point out a correlation between Tillich's understanding of realism in contemporary art and André Bazin's film theory. For these authors, the critics and creative authenticity of art depends on its temporal and spatial relationship with the real, although it does that in a symbolic way. In
\end{abstract}

* Doutor em Teologia, professor na Universidade Federal de Sergipe (UFS) associado ao Programa de Pós-Graduação em Ciências da Religião e ao Programa de Pós-Graduação Interdisciplinar em Cinema da UFS. Email: jmgsantos@yahoo.com.br. Lattes: lattes. cnpq.br/5359207133765624. 
order to develop this study, we will present arguments of Bazin in favor of cinematographic realism and then establish conceptual connections with Paul Tillich.

Keywords: Film theory. Theology of culture. Andre Bazin. Paul Tillich

\section{Introdução}

Uma situação inusitada, Paul Tillich no cinema. Toda a atenção que ele dedicou à arte contemporânea, ao longo dos anos de 1920 e posteriormente, manteve-se bastante circunstanciada, em termos de técnicas e estilos. Sua teologia da cultura passou longe de considerar o cinema. Mesmo no período nos EUA, a partir de 1933, contexto ímpar para o desenvolvimento técnico e estilístico do cinema que dava lugar a um empreendimento crítico renovado direcionado à cultura visual e audiovisual, a sétima arte passou ao largo das análises existenciais e religiosas de Tillich.

Assim que, no conjunto dos escritos que compõe a teologia da arte de Tillich, vamos encontrar motivos tanto para provocar um encontro com o cinema, quanto para evita-lo. Por um lado, há elementos na teologia da arte de Tillich que parecem respaldar a relevância existencial-religiosa do cinema e seu significado teológico para o século XX e XXI. Por outro lado, as próprias noções em que a análise tillichiana da arte se assenta sugerem limites e nos convidam a pensar em que medida seus pressupostos se aplicam produtivamente a uma interpretação teológica do cinema.

Trata-se de um divisor de águas metodológico identificado pela crítica de John Dillenberg, referido por Russel Manning em seu capítulo sobre a teologia da arte de Tillich no Cambridge Companion:

Para muitos de nós, teólogos/as, Tillich tornou o visual um aspecto fundamental, precisamente por causa de sua deslumbrante interpretação teológica. Mas nisso reside também o principal problema, pois uma interpretação teológica que se baseie numa visão sem fidelidade às próprias obras de arte, não é convincente para os críticos e historiadores da arte (DILLENBERG, 1987 apud MANNING, 2005, 164 - tradução e grifo nosso) ${ }^{1}$.

\footnotetext{
Do original: "Tillich made the visual vital for many of us (theologian) precisely because of his dazzling theological interpretation. But therein was also the major problem, for a theological interpretation that is grounded in theological seeing without faithfulness to the artworks themselves is unconvincing to critics and art historians".
} 
Crítica severa, se considerarmos o tamanho investimento de Tillich em justamente realizar uma síntese entre cultura e religião, a partir de seu característico modo de pensar correlacional e dialogal. Mas, nessa abordagem, como destaca Pieper ao tratar da relação entre cinema e religião a partir de Tillich, "no frigir dos ovos, o filme é usado como meio para se chegar a intencionalidades alheias" (PIEPER, 2015, p. 30). Ainda que possamos nos perguntar se, depois do que a semiótica e a psicanálise nos ensinou, alguma abordagem teórica escapa a esse risco, é sob este aspecto que a infidelidade apontada por Dillenberg toca numa questão fundamental: se, como Tillich mesmo defende, o sentido religioso mediado pela obra de arte é definido em um estilo próprio, independente de uma definição estilística em termos formais e estéticos como é própria à crítica e à história da arte (MANNING, 2005, p. 165), isso não implicaria numa abordagem heterônoma da obra de arte - a despeito de todo o esforço para evita-lo - por parte da teologia? Noutras palavras, se Tillich, na base da "ideia sobre uma teologia da cultura", refuta uma ética teológica distinta e concomitante à ética filosófica ${ }^{2}$, a fim de superar o problema de uma esquizofrenia ética e epistemológica, a noção de um "estilo religioso" distinto do estilo definido em termos formais, não incorre justamente numa esquizofrenia estética?

A partir desta questão fundamental, o que proponho aqui é explorar as possibilidades de correlação entre a teologia da arte e o cinema, considerando a hipótese de uma convergência entre o teólogo e o teórico de cinema em torno da compreensão do realismo estético. Sem pretender esgotar essa questão, vamos, primeiro, reconhecer a pertinência do cinema como objeto de uma teologia da cultura (a despeito do desinteresse pessoal de Tillich), dando destaque ao "novo realismo" que, também no cinema, influenciou as estéticas modernas. Em seguida, traçaremos relações entre as noções de realidade, símbolo e revelação na teoria de cinema de André Bazin, que se destacou como teórico do cinema moderno - isto é, o cinema realista. A partir destes elementos,

2 "Von Alters her stand in der systematischen Theologie neben der Dogmatik die theologische Ethik. In der neueren Theologie zerfällt das System gewöhnlich in Apologetik, Dogmatik und Ethik. Was ist das für eine eigenartige Wissenschaft, die sich neben die allgemeine philosophische Ethik als theologische stellt?" (TILLICH, 1990a, p. 72). 
vamos identificar convergências teóricas e questões críticas a serem consideradas numa aproximação a Tillich, com intuito de pensar, com ele e para além dele, uma teologia do cinema hoje.

\section{O cinema como objeto da teologia da cultura}

Por suas implicações sociológicas e antropológicas, não há dúvida quanto à relevância do cinema para uma percepção da situação cultural contemporânea: é justamente dessa relação (entre cinema e realidade) que bebeu toda a teoria de cinema ao longo do século XX. Pensando tillichianamente, significa reconhecer o valor heurístico do cinema, ao menos como sintoma de perguntas da situação cultural da qual participa (TILLICH, 2005, p. 21). Isto, contudo, ainda manteria o cinema distante daquelas possibilidades de sentido religioso que Tillich via na arte em suas análises mais engajadas, especialmente em relação ao expressionismo. Nestas, segundo Tillich, havia uma qualidade revelatória; mais que sintoma de busca e pergunta, o expressionismo consistia numa sedimentação kairótica de encontro e resposta.

A possibilidade de uma teologia do cinema, nesses termos, implica em pensar a partir de certa experiência estética com o cinema, isto é, pensa-lo de modo semelhante a como Tillich pensou a arte que ele vivenciou em suas próprias circunstâncias. Quer dizer, reconhecendo a pertinência das ponderações críticas de Dillenberg, o ponto de partida para uma abordagem teológica do cinema é dado pelo próprio Tillich, ainda que não realizado pelo mesmo. Embora o cinema não esteja no escopo de seu interesse, as mediações que ele nos fornece permite-nos percebe-lo dentre aquelas produções culturais religiosamente significativas em nossa época, "pensando na compreensão existencial da religião e não na teórica” (TILLICH, 2009, p. 81).

Pois, recorrendo a terminologia de Tillich, podemos identificar no cinema arranjos de formas audiovisuais e temas da realidade por meio dos quais estilos artísticos se expressam, tornando-o também um "documento da existência religiosa" de nosso tempo (TILLICH, 1990e, p. 335). Além disso, na dimensão formal, a própria técnica fotográfica (implicada no cinema), com seu apelo ao realismo da imagem, traduziu uma das facetas espirituais mais significativas da contemporaneidade, pelo modo com que tal realismo mecânico se conjugou, em profundo 
contraste para com a modernidade iluminista, com o investimento na ficção, no simbólico e no imaginário.

E aqui, vale lembrar, o símbolo tem um lugar fundamental na filosofia da religião e da cultura de Tillich (1987a, p. 133): é a mediação por meio da qual a atividade cultural condiciona em linguagem aquilo que se experimenta incondicionalmente. A rigor, tal paradoxo incide sobre toda criatividade humana, ou seja, sobre toda a ação cultural (TILLICH, 1987a, p. 134-35). E, segundo Tillich, está presente na arte, em sentido tão semiótico quanto ontológico: o que se diz do mundo, determina o mundo existencial e historicamente. Daí, uma relação íntima e muito cara para Tillich entre realidade, símbolo e revelação:

[o símbolo] nos leva a dimensões da realidade que, não fosse ele, nos permaneceriam inacessíveis. Toda arte cria símbolos para uma dimensão da realidade que não nos é acessível de outro modo (TILLICH, 2001, p. 31)3.

É preciso considerar, porém, que tal dimensão revelatória da criação simbólica incide justamente no que Deleuze (2005, p. 162-163), a respeito do cinema, chamou de "potência do falso" que, contrariando um princípio de identidade, "não é separável de uma irredutível multiplicidade. 'Eu é outro' substituiu Eu=Eu”. Assim, o que é revelado é inventado, postulado:

No cinema, as relações entre visível e invisível, a interação entre o dado imediato e sua significação, tornam-se mais intrincadas. A sucessão de imagens criada pela montagem produz relações novas a todo instante e somos sempre levados a estabelecer ligações propriamente não existentes na tela. A montagem sugere, nós deduzimos (XAVIER, 2003, p. 33).

Nessa dinâmica, é preciso integrar de modo determinante não apenas um jogo intersubjetivo na experiência do cinema, mas a subjetivi-

Tillich, seguindo a citação acima em Dinâmica da fé, bem como em outros escritos, define a especificidade do símbolo religioso a partir da noção de incondicionalidade do sentido (TILLICH, 2001, p. 32s). O símbolo será religioso na medida em que revela/esconde a dimensão incondicional da realidade experimentada pelo ser humano. Isto é, o incondicional define a qualidade normativa (não substancialmente) que determina a realização de sentido nas ações culturais, orientando a consciência humana à autotranscendência (que, por si mesma, é simultaneamente fundamento e abismo, possibilidade e limite, objeto do desejo e signo da falta constitutivos da realidade porque determinantes da subjetividade humana). 
dade criativa tanto do artista quanto do espectador. A realidade que é revelada no filme é, de algum modo, visada e se dá na comunicabilidade simbólica mediada pelo filme.

\section{Realidade, símbolo e revelação no cinema}

A reivindicação de um caráter revelatório do cinema não é, por sua vez, uma prerrogativa da teologia, e está tão presente na história do cinema quanto o apelo à realidade que lhe é próprio. Ismail Xavier sublinha que essa qualidade realista deriva, paradoxalmente, do poder representacional (e nesses termos, revelatório) do cinema, que combina a ilusão de movimento com a objetividade da imagem fotográfica:

Se já é um fato tradicional a celebração do "realismo" da imagem fotográfica, tal celebração é muito mais intensa no caso do cinema, dado o desenvolvimento temporal de sua imagem, capaz de reproduzir, não só mais uma propriedade do mundo visível, mas justamente uma propriedade essencial à sua natureza - o movimento (XAVIER, 2005, p. 18).

Um nome especialmente associado à teorização deste realismo apontado acima foi André Bazin (França, 1918/1958). Seu engajamento com o cinema demarcou a guinada estética ao chamado "neo-realismo" no cinema, na medida em que identificou elementos formais e estilísticos de toda uma cinematografia distinta daquela (o cinema clássico norte-americano) baseada na montagem e numa intenção discursiva/ narrativa - aquela que Xavier (2003, p. 38) identifica como coroamento do melodrama, o "olhar tal como constituído no drama burguês".

Esse tipo de cinema, segundo Bazin, rendeu uma simplificação generalizada da realidade social, histórica, natural ${ }^{4}$ : um recurso ou imagem clichê (do francês, cliché, que alude a constituição de algo na repetição) pelo que sugere repetição excessiva, criando um regime simbólico (Tillich chamaria de "regime de sinais" em distinção a seu

4 A teoria do cinema de Bazin, a despeito de sua coerência teórica e erudição, é fundamentalmente feita de ensaios críticos relacionados a filmes específicos, em um estilo muito próprio às suas preocupações humanistas e pedagógicas em relação ao cinema - e que o torna fundador do "cine-clubismo". No Brasil, temos publicadas algumas coletâneas de seus escritos; para uma percepção de suas críticas e sua proposta estética, destaco os textos reunidos por Mário Alves Coutinho em André Bazin: o realismo impossível, especialmente na sessão O cinema da ocupação e da resistência (BAZIN, 2016, p. 155-198). 
conceito ontológico de símbolo) comum de narratividade, performances, enquadramentos etc. Um novo cinema surge, para o teórico militante Bazin, com uma vocação profética para educar a percepção humana à complexidade do mundo. O princípio para isso é a realidade: o cinema a ser celebrado é aquele fiel a sua matéria-prima, a saber, o registro de eventos em sua duração, em sua riqueza de detalhes, em suas possibilidades de sentido. Assim, o potencial de sentido de realidade do cinema se baseia na fotografia e na sua ontologia direta:

É a gênese mecânica da fotografia que confere a ela suas propriedades específicas em relação à pintura. Pela primeira vez o realismo da imagem alcança a objetividade integral e faz da fotografia um tipo equivalente ontológico do modelo (BAZIN, 2016, p. 181).

Isso porque as imagens que vemos no cinema não são produção do ser humano, como a pintura, escultura, teatro etc. Na fotografia, a natureza das coisas se dá ao olhar quando capturadas pela objetiva da câmera e registradas sobre a película ou em pixels e bits digitais. A luz incidindo sobre as coisas, natureza viva. Se a fotografia já causou uma revolução na percepção "objetiva do mundo", o cinema, com a imagem em movimento, exponenciou esse potencial de sentido.

Ao mesmo tempo, contudo, Bazin admite que o cinema realista tem com a realidade uma relação indireta, pois que mediada pela imagem:

[...] esse "realismo" não significa de maneira nenhuma, bem ao contrário, uma renúncia ao estilo; ele postula somente que a expressão no cinema deve ser dialeticamente conjunta a um suplemento da realidade, e não a um suplemento de artifício (BAZIN, 2016, p. 124 - grifo meu).

Este é o argumento que Coutinho, cuja pesquisa tem dedicado à obra teórica de Bazin, enfatiza contra uma compreensão ingênua de Bazin; este, segundo o pesquisador, "insiste no fato de que o realismo nunca é dado de graça, automaticamente; ele é também uma construção" (COUTINHO, 2016, p. 22), que implica na ruptura com a positividade de distinção entre o real e o simbólico na imagem. Nas palavras de Bazin (2016, p. 90 - grifo meu), trata-se de um realismo que "não é 
o da cópia, mas uma reinvenção da exatidão" que se afasta do convencional para se valer de uma abordagem documental e simbólica simultaneamente.

Esta é a dimensão simbólica implicada na arte enquanto ação de linguagem, como apontamos acima, a partir de Tillich, na qual incide sua qualidade revelatória. Isto é, não se trata de reproduzir fielmente a realidade, mas dar a ver um encontro com a realidade, tomando como pressuposto que esta é sempre algo a ser decifrado porque repousa em ambiguidades, paradoxos, mistérios.

Por conta disso, Bazin destaca o papel da "profundidade de campo" - que não apenas denota uma convergência com a linguagem estética de Tillich, mas se aproxima da sua noção ontológica de vida marcada pela noção de ambiguidade (TILLICH, 2005, p. 475s). Junto deste recurso estilístico, outro surge relativo ao tempo: o plano-sequência ${ }^{6}$, que a partir desta orientação à realidade passará a explorar a força expressiva da duração da imagem fílmica (planos/sequências).

Significativo para nosso argumento aqui é que, os filmes que recorrem a essas formas cinematográficas tendem a, no lado da recepção, provocar estranhamento e exigir uma atitude mais ativa e criativa por parte do olhar/escuta do/a espectador/a. Para Bazin, nesse sentido, privilegiar a profundidade de campo e o plano-sequência não significa mera simplificação objetivante da linguagem cinematográfica, mas uma econo-

5 Profundidade de campo é uma noção óptica que define pontos de distância numa imagem a partir de uma ou mais partes mais claras. Foi usada na primeira geração do cinema clássico e praticamente abandonada posteriormente. Nos anos de 1940, sua retomada causou um efeito de novidade estética, em grande medida movido pela crítica de Bazin que "postulou que ela produzia um 'a-mais-de-real' quantitativo (mais partes claras na imagem) e qualitativo (um respeito maior pela 'ambiguidade ontológica da realidade'); em tese foi vivamente criticada na década de 1960, por vários autores que observaram que, sendo o realismo sempre uma noção inteiramente convencional e não absoluta, a profundidade de campo não podia ter um valor tão unívoco" (AUMONT; MARIE, 2012, p. 243).

6 Plano-sequência define um "plano bastante longo e articulado para representar o equivalente a uma sequência. [...] Do ponto de vista estético, ele foi defendido (a propósito de Welles e Wyler) por André Bazin, que via nele, junto com a profundidade de campo, um instrumento do realismo, que permitia evitar a fragmentação do real e respeitava, portanto, a um só tempo, o próprio real e a liberdade do espectador" (AUMONT; MARIE, 2012, p. 231). 
mia simbólica orientada ao encontro do olhar com o mundo: primeiro, o olhar da câmera, depois este em relação ao olhar do espectador ${ }^{7}$.

É nesse encontro "revelatório" entre imagem do real e espectador que reside, portanto, a possibilidade realista do cinema. Bazin celebra o cinema que "vem a ser a consecução no tempo da objetividade fotográfica" porque, desse modo, a experiência com "a imagem das coisas é também a imagem da duração delas" - do que resulta:

As virtualidades estéticas da fotografia residem na revelação do real. $\mathrm{O}$ reflexo na calçada molhada, o gesto de uma criança, independia de mim distingui-los no tecido do mundo exterior; somente a impassibilidade da objetiva, despojando o objeto de hábitos e preconceitos, de toda a ganga espiritual com que a minha percepção o revestia, poderia torna-lo virgem à minha atenção e, afinal, ao meu amor. Na fotografia, imagem natural de um mundo que não sabemos ou não podemos ver, a natureza, enfim, faz mais do que imitar a arte: ela imita o artista (BAZIN, 1983, p. 126-127-grifos meus).

Para Bazin, portanto, a realidade contém algo em si mesma, que é de caráter qualitativo, próximo ao que Tillich chamou de Gehalt, o conteúdo substancial do sentido, o "poder inerente das coisas" (TILLICH, 1987b, p. 194). O princípio revelatório do cinema, para Bazin, não precisa de justificativa teológica, pois decorre de um axioma ontológico. É um pressuposto que ele assume como "necessidade mental de ilusões" (BAZIN, 1983, p. 127), cuja finalidade é uma só: amar a realidade e apreender uma realidade que possa ser amada. Ou seja, ele permanece no horizonte da produção de sentido, que por meio de luzes projetadas numa tela podem ter consequências tão estéticas quanto éticas, decisivas para a subjetividade e a experiência de mundo.

\footnotetext{
7 "Bazin está incluindo o espectador na sua definição do realismo cinematográfico. É ele que vê, escolhe o mais importante, liga o que vê, em resumo, dá sentido ao filme [...] De passagem, é bom ressaltar que, ao tomar essa posição, Bazin está afirmando, mais uma vez, que o realismo da câmera pode ser em parte automático, mas que o realismo do cinema depende de algo mais: é também construto, uma retórica, também do espectador" (COUTINHO, 2016, p. 27).
} 


\section{Revelação como hermenêutica da realidade}

A teologia da arte de Tillich pressupõe que a obra de arte, enquanto resultado de uma ação criativa e comunicativa, é ela mesma materialização de consciência de sentido. Nestes termos, ela consiste essencialmente de forma (Form) e conteúdo formal (Inhalt/Content), ambos definindo os elementos objetivos da obra, sua forma e seu tema. Sua dimensão comunicativa, contudo, implica uma qualidade ou força que "age" na obra de arte, que é o conteúdo substantivo (Gehalt/Import) do sentido intuído pelo artista e encontrado pelo espectador, cada qual criativa e subjetivamente.

As dimensões da forma e do conteúdo definem as criações culturais em sua "condicionalidade": é aquilo que torna as "coisas" o que são, definindo-as por suas qualidades perceptivas ao ser humano. A dimensão substantiva do sentido - que Tillich chama também de "poder inerente das coisas", como vimos acima, é o que determina a relevância destas por seu sentido em termos existenciais: é o que qualifica certas criações e experiências pelo significado que ganham e comunicam, seja pela positividade ou negatividade implicada. Tillich sublinha esse caráter com o que chama de "choque ontológico" (TILLICH, 2005, p. 126): aquelas situações em que o sujeito é tomado pela percepção da possibilidade iminente de total desencontro com o sentido de mundo e de sua própria existência - a "ameaça de não ser" irrompe na obra de arte ou, por meio dela, se torna "transparente" em relação à realidade.

Assim, o interesse teológico em relação ao cinema - tal como a cultura, de modo geral - tem de ser determinado pela compreensão da natureza incondicional e da função dinâmica desta dimensão substantiva do sentido, a Gehalt, latente em determinados filmes, linguagens e estéticas de cinema. Sua natureza é incondicional porque ela é o "fundamento" de infinita possibilidade de sentido; e sua função é dinâmica porque, ao mesmo tempo, exige infinita realização de sentido - o que a torna, além de fundamento, abismo de sentido. Com esse pressuposto, entende-se o que Tillich quer dizer quando afirma que "cultura" define a orientação da consciência de sentido ao que é condicionado, enquanto "religião" define a orientação da consciência à incondicionalidade de sentido (TILLICH, 1987a, p. 134-35). Na compreensão de Tillich, ambas orientações da consciência podem se materializar numa obra 
de arte; isto é, em relação ao cinema, a tarefa da teologia da arte seria então perceber e interpretar existencial e religiosamente os sinais e os vestígios de Gehalt (a incondicionalidade de sentido) nas formas e nos temas evocados em terminada filmografia.

A partir desses conceitos, nota-se que a correlação pretendida pela teologia deixa de ser meramente procedimental. Ela ganha um aspecto vívido e circunstanciado pelas subjetividades em questão: o olhar e a escuta teológica estariam, assim, atentas àquelas criações culturais em que ressoa perguntas de uma consciência voltada à questões últimas e incondicionais. Além disso, dada a natureza simbólica da arte, não apenas "perguntas" mas também "respostas" podem ser encontradas em sua expressividade. E nesse quesito, a arte - ao lado da filosofia e da religião - é insuperável:

[...] a arte é a mais clara indicação da auto-interpretação de uma determinada situação; se a cultura como um todo é a expressão da totalidade da auto-interpretação criativa da humanidade, é na arte que o caráter dessa atividade auto-interpretativa torna-se mais claramente visível (MANNING, 2009, p.156).

Na Teologia Sistemática, Tillich (2005, p. 519) atribui à linguagem o acesso privilegiado para "a vida na dimensão do espírito". A arte, por sua natureza metalinguística, ganha relevância sob esse argumento. E o cinema, um lugar particular, por suas propriedades psicológicas e antropológicas que identifica seu processo criativo e sua recepção com o funcionamento do próprio espírito humano: um filme é um ponto de vista em movimento, uma visão objetiva e uma vidência acerca da realidade.

Nota-se, com esse argumento, que a qualidade hermenêutica não apenas move o olhar e a escuta teológica, mas caracteriza e qualifica a criatividade artística. Um elemento fundamental da teologia da arte de Tillich é que a qualidade hermenêutica implicada nessa definição de teologia é marcada por uma "atitude receptiva de revelação" que é encontrada na obra de arte. O interesse pela arte se dá a partir daquilo que ela possivelmente media e pelo que espera ansiosamente encontrar o/a teóloga envolvida nessa situação comunicativa com a obra em questão. Ou seja, revelação é o sentido que se dá comunicativamente: "é invariavelmente revelação para alguém numa situação 
concreta" (TILLICH, 2005, p. 123). À atitude receptiva de revelação que determina a definição hermenêutica da teologia da arte em Tillich corresponde, portanto, uma qualidade revelatória da obra de arte que é de natureza também hermenêutica.

Nesses termos, um filme sempre sedimenta formal e estilisticamente um determinado encontro do ser humano com o mundo e consigo mesmo, traz consigo uma autocompreensão humana - seja por mera imitação e reprodução ou por meio de uma hermenêutica crítica e criativa da existência; segundo Tillich, a significatividade existencial dessa interpretação, isto é, o poder de sentido desta autocompreensão repousa na potência incondicional de sentido que é "fundamento e abismo" crítico e criativo. Essa potência incondicional, por sua vez, se manifesta e/ou se revela na medida em que a subjetividade do artista se expressa como preocupação última e a subjetividade do/a teóloga a recebe estética e teoricamente.

Por sua vez, a qualidade teológica da obra de arte implica naquilo que Tillich definiu como estilo: é por meio do estilo desenvolvido pelo artista, no resultado formal e temático na obra de arte, que a dimensão substantiva do sentido (Gehalt) poderá se manifestar. Daí que o elemento incondicional de sentido é que determina o "estilo religioso" de uma obra de arte, e não seu aspecto formal ou seu conteúdo temático. Foi nesses termos que o expressionismo e o novo realismo ocuparam lugar central na teologia da arte de Tillich nos anos 1920: ambos, para Tillich, revelam o potencial criativo e transcendente em relação a situação cultural da qual fazem parte - nas suas palavras:

A realidade empírica das coisas é novamente procurada. Contudo, não por ela mesma e sim como expressão da Gehalt objetiva que é o poder inerente das coisas [...] O expressionismo rompeu as formas externas das coisas a fim de expressar sua Gehalt; o Novo Realismo volta-se deliberadamente à forma externa a fim de mostrar o poder inerente das coisas em e por meio de sua forma externa. Dessa maneira, suas obras tem uma estranha e geralmente inquietante suspensão entre experiência e transcendência [...] seu sucesso depende do quanto elas não rejeitem nossa situação e apreendam o transcendente, não apenas de modo abstrato 
e paradoxal, mas em poder de vida e com símbolos criativos (TILLICH, 1987b, p. 194) ${ }^{8}$.

Este texto foi publicado em 1928 sob título Über gläubigen Realismus (Sobre o realismo fiel). É ainda um contexto em que, por conta do engajamento de Tillich, sua interpretação teológica da arte parece ainda estar imune à crítica que, no início de nossa reflexão, remetemos. Se um desencantamento posterior encaminha a reflexão de Tillich para argumentos menos históricos e mais existenciais (HIGUET, 2017, p. 168), também no que diz respeito ao potencial teórico de sua teologia da arte, parece que sua produção nos anos de 1920 nos oferece elementos mais significativos para a reflexão hoje. Nesse sentido, destaco, a partir desta citação acima, quatro elementos que sintetizam elementos da teologia da arte de Tillich a partir dos quais podemos desenvolver a relação com o cinema:

Primeiro, o reconhecimento de tendências estéticas nos anos 1920 movidas por um realismo crítico: realismo porque privilegiam a realidade empírica (social, histórica, econômica...), e crítico por fazerem isso almejando um encontro "outro" com o real. Tal compreensão está alinhado com o sentido de realismo que vimos em Bazin, e que, por sua vez, Deleuze também sublinha:

[...] o real não era mais representado ou reproduzido, mas "visado". Em vez de representar um real já decifrado, o neo-realismo visava um real, sempre ambíguo, a ser decifrado; por isso o plano-sequencia tendia a substituir a montagem das representações (DELEUZE, 2005, p. 9).

8 Do original: "Die empirische Realität der Dinge wurde wieder aufgesucht, aber nicht um ihrer selbst willen, sondern als Ausdruck des objektiven Gehaltes, der inneren Mächtigkeit der Dinge. [...] der Expressionismus hatte die äußere Form zerbrochen, um den inneren Gehalt auszudrücken; der neue Realismus wendet sich in voller Hingabe an die äußere Form, um in ihr und durch sie die innere Mächtigkeit der Dinge zu schauend. Darum haben ihre Werke ein eigentümliches, oft unheimliches Schweben zwischen Erfahrung und Transzendenz. Der unbewußte Kunstwille strebt einem gläubigen Realismus zu. Zahllose Tendenzen formaler und inhaltlicher Art durchkreuzen diese Entwicklung. Und schließlich hängt ihr Erfolg davon ab, inwieweit es unserer Zeit überhaupt vergönnt ist, die Unbedingtheit der Transzendenz zu erfassen, und zwar nicht nur in Abstraktion und Paradoxie, sondern lebensmächtig und symbolkräftig”. 
É nessa orientação à realidade que Tillich identifica o elemento teológico na arte expressionista e neo-realista: uma realidade "visada" porque, para Tillich, está orientada à incondicionalidade de sentido do real, isto é, o que se percebe e se deseja da realidade: seu poder inerente e incondicional.

O segundo elemento a destacar são as tendências estéticas nas quais Tillich percebe esse princípio atuando, o Expressionismo e o Neo-Realismo. O primeiro, embora tenha sido determinante para o cinema alemão dos anos 1920, não se consolidou significativamente (permaneceu dependente demais do teatro, da arquitetura e da literatura, e por sua opção plástica foi alvo de crítica de Bazin). Contudo, o neo-realismo, já vimos com Bazin, foi significativo e teve lugar marcante no cinema contemporâneo.

O terceiro elemento a ser destacado é a consideração geral que Tillich faz à recepção estética dessas obras de arte. Evidencia, com isso, a dimensão comunicativa da experiência estética, colocando os pólos de sujeito/objeto em uma correlação determinante. E nesse caso, trata-se de uma experiência estética e comunicativa marcada pela ideia de estranhamento e inquietação - isto é, baseada numa qualidade crítico-negativa, a mesma que Tillich valoriza em seus destaques de aspectos protestantes da arte (pintura) contemporânea (TILLICH, 1990bcd, p.197-207; 269-279; 297-302).

O quarto destaque relativo à citação acima é o que, nela, Tillich considera quanto ao sucesso dessas propostas artísticas depender de uma adequada conexão delas com seu tempo e lugar enquanto, ao mesmo tempo, "apreendem o transcendente". Trata-se da intuição que ele tanto valoriza na arte, quanto à expressão do "poder inerente das coisas" vinculada a suas condições reais, histórica e existencialmente.

\section{Conclusão}

O realismo é uma tendência onipresente no cinema desde sua origem. E a definição de realidade, bem como da relação do espírito humano com essa realidade, conferiu um repertório riquíssimo de possibilidades estéticas e de linguagens ao longo de um pouco mais de um século, desde o surgimento da sétima arte. É significativo que para uma técnica tão objetivante, seja justamente a fronteira entre realidade 
e imaginário que lhe caracteriza o potencial simbólico desde de suas primeiras e mais rústicas versões.

Dito isso, para tratar do cinema, podemos nos valer da afirmativa de Tillich destacada acima: o cinema nasce também como inclinação e busca pela realidade empírica; uma procura movida também, para muitos artistas, pelo "poder inerente das coisas". Essa percepção poderia ser tomada como chave de leitura da própria história do cinema, seu desenvolvimento estético e teórico ao mesmo tempo, como aqui esboçamos com André Bazin.

Nesse sentido, e para concluir, vale observar como a história do cinema e seu desenvolvimento teórico se desdobram concomitantemente ao desenvolvimento das Ciências Humanas, especialmente no contexto europeu e norte-americano. A psicologia, a filosofia, o pensamento político e econômico do início do século XX, e seus desdobramento nos pós-guerras, especialmente a partir da referência semiótica, psicanalítica e pós-estruturalista: todas essas correntes incidiram em teorias de cinema que, por sua vez, geraram estéticas e linguagens específicas. De modo geral, em todas essas faces do cinema reflexivo - sempre como contraponto de sua versão industrializada - vamos encontrar, implícita ou explicitadamente, a pergunta ontológica e existencial latente no cinema, que diz respeito à relação que ele pressupõe, imita, falsifica e engendra entre ser humano e realidade.

A partir dessa relação, o cinema media, ao lado de outras artes, auto-interpretações criativas da humanidade, que não apenas dão a ver o caráter ambíguo da cultura, mas também seu princípio autotranscendente: aquilo que Tillich chamou de religião, isto é, a orientação do espírito humano para realizar, em meio a seus encontros fragmentados com a realidade, sentidos profundos, que permitam tornar a vida e o mundo algo possível e amável.

\section{REFERÊNCIAS}

AUMONT, Jacques; MARIE, Michel. Dicionário teórico e crítico de cinema. 5.ed. Tradução: Eloísa Araujo Ribeiro. Campinas: Papirus, 2012.

BAZIN, André. O realismo impossível. Seleção, tradução, introdução e notas: Mario Alves Coutinho. Belo Horizonte: Autêntica, 2016. 
BAZIN, André. Ontologia da imagem fotográfica; Morte todas as tardes; À margem de $O$ erotismo no cinema. In. XAVIER, Ismail (org.). A experiência do cinema. Rio de Janeiro: Graal. Embrafilmes, 1983, p. 119-142.

COUTINHO, Mário A. A invenção do realismo, ou Tudo que vive é sagrado. In. BAZIN, André. O realismo impossível. Seleção, tradução, introdução e notas: Mario Alves Coutinho. Belo Horizonte: Autêntica, 2016, p. 15-40.

DELEUZE, Gilles. Cinema II. A imagem-tempo. Tradução: Eloisa de Araujo Ribeiro. São Paulo: Brasiliense, 2005.

HIGUET, Etienne. A teologia da Paul Tillich: utopia, esperança e socialismo. São Paulo: Fonte Editorial, 2017.

MANNING, Russel Re. Tillich's theology of art. In.: MANNING, Russel Re (Ed.). The Cambridge companion to Paul Tillich. Cambridge, UK: Cambridge University Press, 2009, p. 152-172.

PIEPER, Frederico. Religião e cinema. São Paulo: Fonte Editorial. Juiz de Fora: PPCIR/UFJF, 2015.

TILLICH , P. Dinâmica da fé. 6.ed. Tradução: Walter O. Schlupp. São Leopoldo: Sinodal, 2001.

TILLICH, Paul. (a) Religionsphilosophie (1925); (b) Über gläubigen Realismus (1928). In.: CLAYTON, J. (ed.). Paul Tillich Main works/Hauptwerke : writings in the philosophy of religion. Berlim/New York : De Gruyter Evangelisches Verlagswerk BmbH, 1987. v.4, p. (a) 117-170; (b) 193-212.

TILLICH, Paul. Teologia da cultura. Tradução: Jaci Marschin. São Paulo: Fonte, 2009.

TILLICH, Paul. Teologia sistemática. 5.ed. revisada. Tradução: Getúlio Bertelli e Geraldo Korndörfer. Revisão: Enio Mueller. São Leopoldo: Sinodal. EST, 2005.

TILLICH, Paul. (a) Über die Idee einer Theologie der Kultur (1919); (b) Religion and secular culture (1946); (c) Existencialist aspect of modern art (1956); (d) Protestantism and the contemporary style in the visual arts (1957); (e) Zur Theologie der bildenden Kunst und der Architektur (1961). In.: PALMER, M. (ed.). Paul Tillich Main works/Hauptwerke : writings in the philosophy of culture. Berlim/New York : De Gruyter - Evangelisches Verlagswerk BmbH, 1990. v.2, p. (a) 69-86; (b) 197-207; (c) 269-279; (d) 297-302; (e) 333-344.

XAVIER, Ismail. O discurso cinematográfico: a opacidade e a transparência. 3.ed. São Paulo: Paz e Terra, 2005.

XAVIER, Ismail. O olhar e a cena: melodrama, Hollywood, Cinema Novo, Nelson Rodrigues. São Paulo: Cosac \& Naify, 2003. 